\title{
An Adventure in Sustainable Cross-Coupling of Phenols and Derivatives via Carbon-Oxygen Bond Cleavage
}

\author{
Huiying Zeng, ${ }^{* \dagger}{ }^{\dagger}$ Zihang Qiu, ${ }^{\ddagger}, \#$ Alejandra Domínguez-Huerta, ${ }^{\ddagger}, \#$ Zoë Hearne, ${ }^{\ddagger}$ Zhengwang Chen, ${ }^{\S}$ \\ and Chao-Jun $\mathrm{Li}^{*}, \dagger,+0$
}

\footnotetext{
${ }^{\dagger}$ The State Key Laboratory of Applied Organic Chemistry, Lanzhou University, 222 Tianshui Road, Lanzhou, Gansu 730000, China

${ }^{\ddagger}$ Department of Chemistry and FQRNT Centre for Green Chemistry and Catalysis, McGill University, 801 Sherbrooke Street West, Montreal, Quebec H3A 0B8, Canada

${ }^{\S}$ Key Laboratory Organo-Pharmaceutical Chemistry of Jiangxi Province, Gannan Normal University, Ganzhou 341000, China
}

ABSTRACT: Aryl halides are very useful electrophiles for synthesizing various substituted aromatic compounds via metal-catalyzed cross-coupling reactions. Because of the high cost associated with their synthesis and the stoichiometric halide waste produced when using aryl halide feedstocks, cheaper and more sustainable alternatives have been explored, such as phenols. However, phenols have a very reactive hydroxyl group and a $\mathrm{C}-\mathrm{O}$ bond with high dissociation energy. To overcome such challenges, earlier studies focused on finding ways to reduce the energy of the $\mathrm{C}-\mathrm{O}$ bond while removing the active proton by transforming phenols into phenol derivatives (e.g., sulfonates, esters, carbamates, ethers, and metal salts). A greater ambition is to directly cross-couple

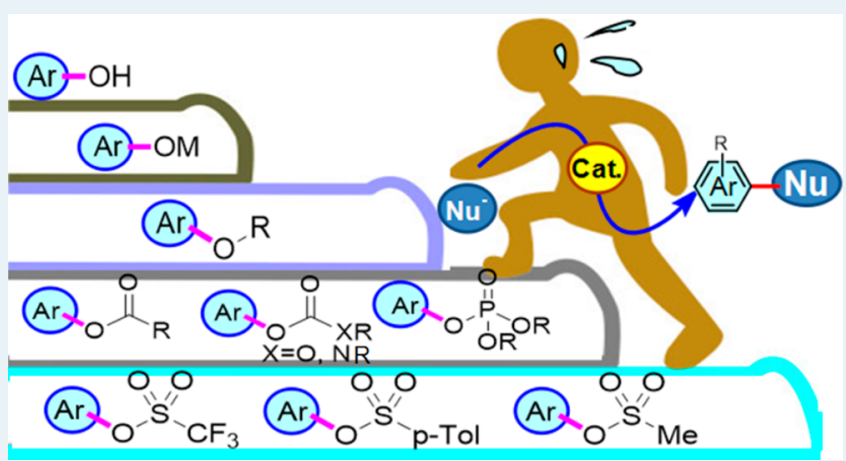
phenols with nucleophiles via $\mathrm{C}-\mathrm{O}$ cleavage. In this Perspective, we briefly summarize efforts and accomplishments concerning the cross-coupling of phenol derivatives and phenols.

KEYWORDS: cross-coupling, phenol, $\mathrm{C}-\mathrm{O}$ cleavage, phenol derivatives, nickel, iron, ruthenium, palladium

\section{INTRODUCTION}

Aromatics are fundamental structural units which are almost ubiquitously present in pharmaceuticals, agrochemicals, electronics, and dyes. ${ }^{1}$ Given the importance of aromatic compounds, numerous efforts have been made to synthesize these compounds via transition-metal-catalyzed cross-coupling reactions since the 1970 s. $^{2}$ In the early stages, aryl halides were popular electrophilic coupling partners because of their high reactivity. However, the additional steps necessary to presynthesize aryl halides from naturally occurring aromatic compounds, and the stoichiometric quantity of halide waste generated from the cross-coupling reaction (Scheme 1a) limits their application in industry. Undoubtedly, taking into account growing concerns on the environment and the sustainability of our society, the development of greener and more naturally abundant alternatives as aromatic feedstocks is highly desirable.

To this end, phenols are good candidates because they are both one of the most abundant aromatic feedstocks from the coal-based chemical industry and one of the basic units of lignin. Thus, they can be easily obtained from natural sources at low costs. However, phenols have a very reactive acidic hydroxyl group and a $\mathrm{C}-\mathrm{O}$ bond with a high-dissociationenergy due to $\mathrm{p}-\pi$ conjugation. Therefore, it is considered necessary to transform phenols into phenol derivatives (e.g., sulfonates, esters, carbamates, ethers, and metal salts) in order
Scheme 1. Cross-Coupling of Aryl Halides with Phenols and Phenol Derivatives
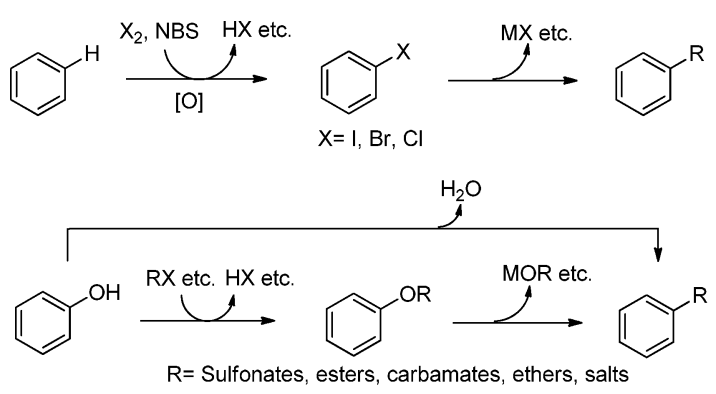

(b)

to overtake this challenge by removing the acidic proton and lowering the energy of the $\mathrm{C}-\mathrm{O}$ bond (Scheme $1 \mathrm{~b}$ ). In recent years, $\mathrm{C}-\mathrm{O}$ electrophiles have emerged as powerful alternatives to aryl halides in the cross-coupling arena. ${ }^{3}$ The possibility of directly coupling phenols with different nucleophiles has also been explored (Scheme 1b). This Perspective briefly summarizes some representative reports in the field of cross-

Received: October 17, 2016

Revised: November 29, 2016

Published: December 2, 2016 
couplings with phenol derivatives and phenols via $\mathrm{C}-\mathrm{O}$ bond cleavage.

\section{CROSS-COUPLING OF PHENOL DERIVATIVES}

2.1. Cross-Coupling with Phenol Sulfonates. Triflates and nonaflates generated from phenols are known to be the most reactive phenol species, almost matching the reactivity of aryl halides. Representative examples using triflates and nonaflates include the Heck, ${ }^{4}$ Buchwald-Hartwig, ${ }^{5}$ Hiyama, ${ }^{6}$ Kumada, ${ }^{7}$ Ullmann, ${ }^{8}$ Negishi, ${ }^{9}$ Sonogashira, ${ }^{10}$ Stille, ${ }^{11}$ and Suzuki-Miyaura ${ }^{12}$ cross couplings. Due to their high reactivity, the use of these compounds as electrophiles has not been included in this review (Scheme 2). ${ }^{3 j, 13}$ Some representative examples using mesylates, tosylates, and sulphamates of phenols are discussed in this section.

Scheme 2. Relative Difficulty of Cross-Coupling with Phenol and Phenol Derivatives

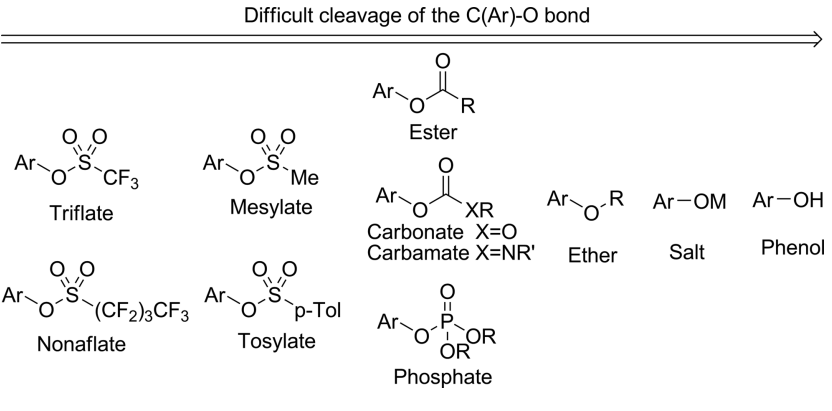

Badone reported the first alternative to aryl triflates using a palladium catalyst to couple aryl 4-fluorobenzenesulfonates with organo-stannanes in a Stille-type reaction (Scheme 3). ${ }^{14}$

Scheme 3. Catalytic Cross-Coupling of Aryl Tosylates with Organostannanes

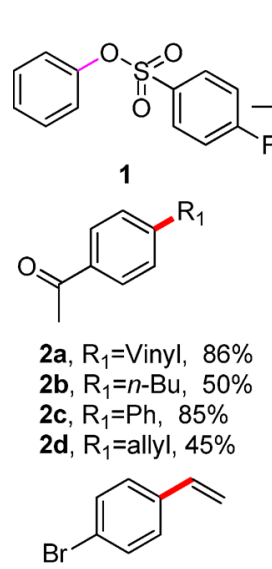

2 g, $25 \%$

$$
\mathrm{R}_{3} \mathrm{Sn}^{-}-\mathrm{R}_{1}
$$

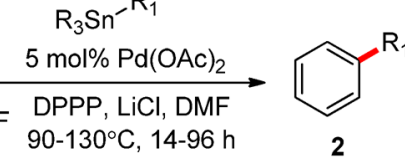

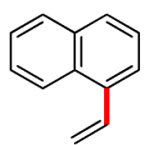

$2 e, 50 \%$<smiles>Cc1cccc(-c2ccccc2)c1</smiles>

2h, $41 \%$<smiles>c1ccc(-c2cccnc2-c2ccccc2)cc1</smiles>

2f, $68 \%$<smiles>C=Cc1ccc(OCC)cc1</smiles>

$2 \mathrm{i}, 12 \%$
The yields varied greatly depending on the nature of aryl substitution: aryl benzenesulfonates substituted with electrondonating groups gave very poor yields, whereas cross-coupling was efficient for those bearing other substituents. The tolerated nucleophiles included alkyl-, vinyl-, allyl-, and arylstannanes.

Many examples have been reported concerning the crosscoupling of aryl tosylates, mesylates, and sulfamates with different nucleophiles (Scheme 4). Representative examples include homodimerizations ${ }^{15}$ and coupling with Grignard
Scheme 4. Cross-Coupling Reactions of Aryl Tosylates and Mesylates with Other Nucleophiles

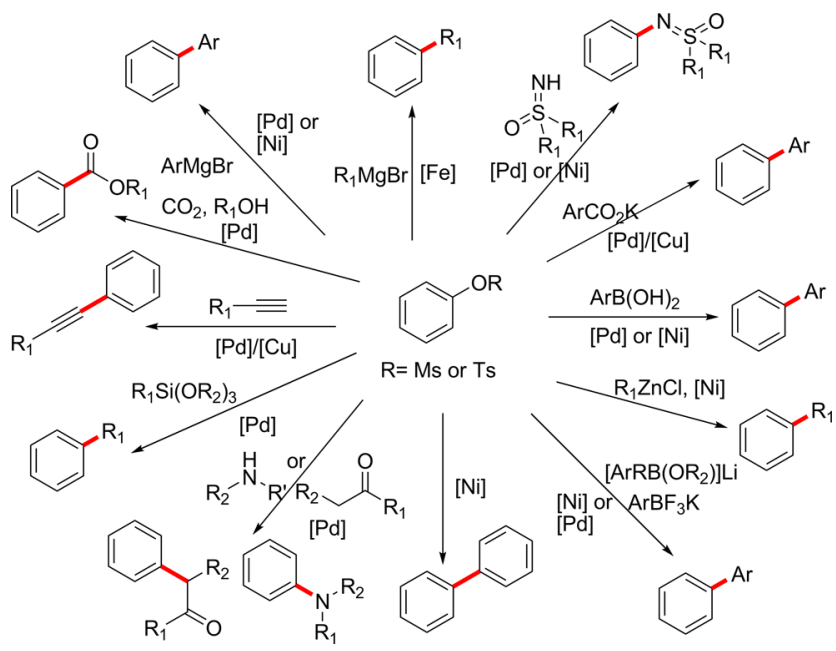

reagents (catalyzed by $\mathrm{Ni}$ or $\mathrm{Pd},{ }^{16} \mathrm{Fe}^{17}$ ), ketones and amines, ${ }^{18}$ boronic acids, ${ }^{19}$ terminal alkynes, ${ }^{20}$ potassium aryltrifluoroborates, ${ }^{21}$ lithium organoborates, ${ }^{22}$ carbon dioxide, ${ }^{23}$ benzylic zinc reagents, ${ }^{24}$ arylsilanes, ${ }^{25}$ aromatic carboxylate salts, ${ }^{26}$ and sulfoximines. $^{27}$

Two cross-coupling examples with aryl tosylates involving $\mathrm{C}-\mathrm{H} / \mathrm{C}-\mathrm{O}$ bond cleavage are illustrated in Scheme 5. ${ }^{28,29}$ One

Scheme 5. Cross-Coupling Reactions of Aryl Tosylates and Mesylates with Arenes and Heteroarenes via $\mathrm{C}-\mathrm{H}$ Bond Activation

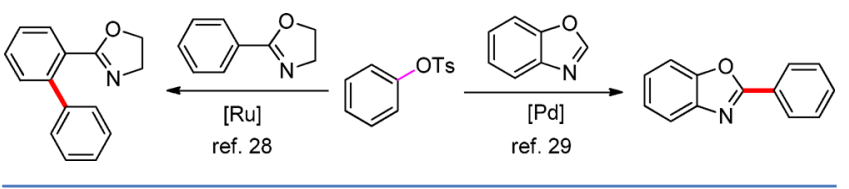

comprises an ortho-directed ruthenium-catalyzed arylation reaction with aryl tosylates via $\mathrm{C}-\mathrm{H}$ bond activation, ${ }^{28}$ while the other is a palladium-catalyzed direct arylation of heteroarenes with tosylates and mesylates. ${ }^{29}$

2.2. Cross-Coupling with Phosphates of Phenols. In 1981, Kumada's group reported the cross-coupling of aryl phosphates with Grignard and organo-aluminum reagents (Scheme 6). ${ }^{30}$ Aryl phosphates were converted into alkyl-, alkenyl-, and arylbenzenes in high yields in the presence of nickel catalysts. In 2009, Nakamura reported that hydroxyphosphine ligands greatly accelerated the nickel-catalyzed cross-coupling reaction of Grignard reagents with aryl electrophiles possessing low reacivity. ${ }^{31}$ Aryl halides such as fluorides, chlorides, polyfluorides, and polychlorides, as well as phenol derivatives such as carbamates and phosphates can be utilized in this reaction.

The cross-coupling of phenol phosphates with arylboronic acids $^{32}$ and amines ${ }^{33}$ has been reported, as has the crosscoupling of phenol phosphoramides with boronic acids. ${ }^{34}$ These reactions are summarized in Scheme 7.

In addition to transition-metal catalysis, Fagnoni and coworkers reported metal-free cross-coupling reactions of aryl phosphates and sulfonates through photoheterolysis of the carbon-oxygen bond (Scheme 8), ${ }^{35}$ offering an appealing method for the phenylation of alkenes and arenes substituted with electron-donating groups. 
Scheme 6. Cross-Coupling of Aryl Phosphates with Grignard Reagents
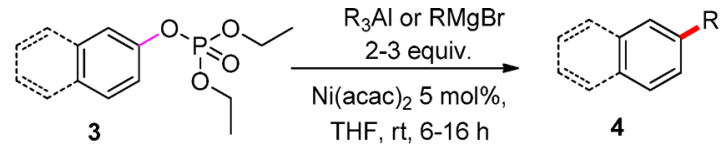

THF, rt, 6-16 h
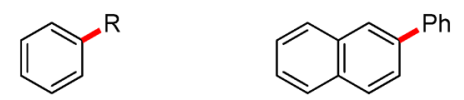

4a, $\mathrm{R}=\mathrm{CH}_{2} \mathrm{SiMe}_{3}, 77 \%$

4b, R=p-MePhenyl, $91 \%$

$4 c, 75 \%$<smiles>CCc1ccc(-c2ccccc2)cc1</smiles>

$4 h, 56 \%$<smiles>COc1ccc(CN(C)S(=O)(=O)[O-])cc1</smiles>

$4 i, 54 \%$

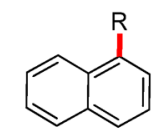

4d, $\mathrm{R}=\mathrm{CH}_{2} \mathrm{SiMe}_{3}, 79 \%$

4e, $\mathrm{R}=\mathrm{Ph}, 77 \%$

4f, $\mathrm{R}=\mathrm{Bn}, 80 \%$

4g. $\mathrm{R}=\mathrm{n}-\mathrm{Bu}, 82 \%$

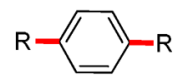

4j, $\mathrm{R}=\mathrm{CH}_{2} \mathrm{SiMe}_{3}, 52 \%$ 4k, $\mathrm{R}=\mathrm{Ph}, 80 \%$

Scheme 7. Cross-Coupling of Aryl Phosphates with Various Nucleophiles

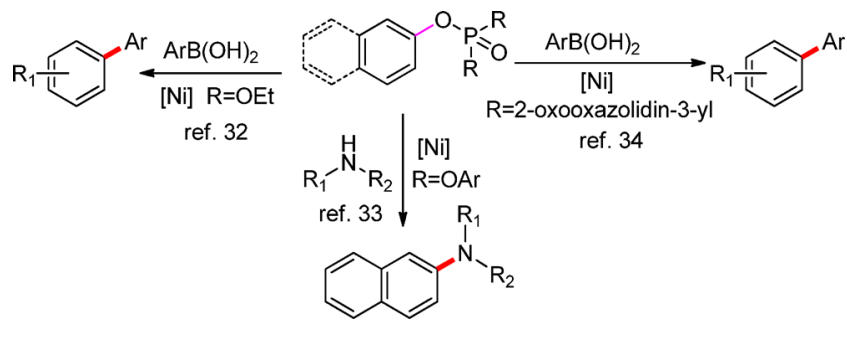

Scheme 8. Metal-Free Cross-Coupling Reactions of Aryl Phosphates with Arenes

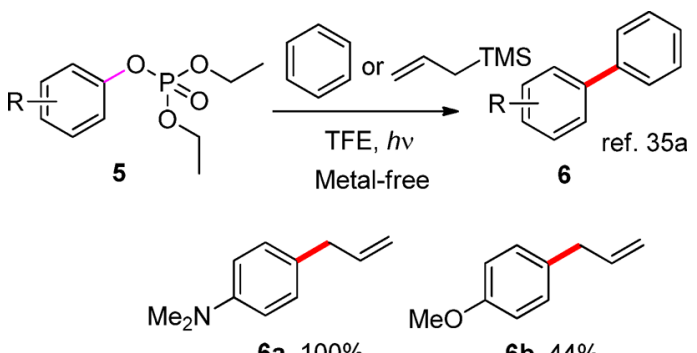<smiles>CN(C)c1ccc(-c2ccccc2)cc1</smiles>

$6 \mathrm{c}, 96 \%$<smiles>COc1ccc(-c2ccccc2)cc1</smiles>

6d, $96 \%$

2.3. Cross-Coupling with Carbamates and Carbonates of Phenols. In 1992, Snieckus reported the first $\mathrm{Ni}(0)$ catalyzed cross-coupling reaction of aryl $O$-carbamates and aryl triflates with Grignard reagents (Scheme 9). ${ }^{36}$ A wide variety of aromatic, fused aromatic, heterocyclic carbamates, and complex polysubstituted aromatics were coupled efficiently using this method. The cross-coupling of phenol carbamates and carbonates with other nucleophiles has since been reported. For example, the Ni-catalyzed borylation of aryl and alkenyl carbamates with neopentylglycolborylates; ${ }^{37}$ the Fe-catalyzed cross-coupling of alkenyl and aryl carboxylates with Grignard reagents; ${ }^{38}$ nickel- and rhodium-catalyzed Suzuki-Miyaura coupling of aryl carbamates, carbonates, and sulfamates; ${ }^{39}$ cobalt-catalyzed direct arylation and benzylation (via $\mathrm{C}-\mathrm{H} / \mathrm{C}-$ O cleavage) with sulfamates, carbamates, and phosphates; ${ }^{40}$ and

Scheme 9. Cross-Coupling Reactions of Aryl Carbamates and Carbonates with Grignard Reagents

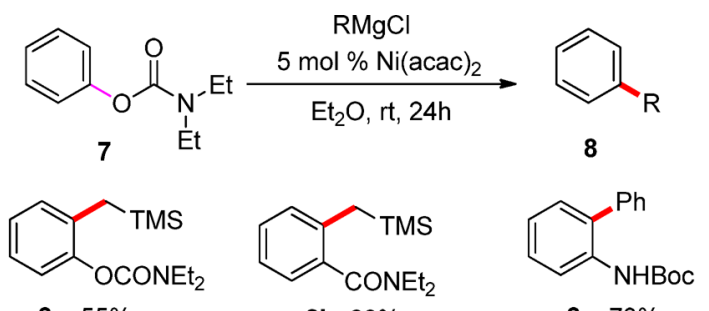

8 a, $55 \%$

8b, $60 \%$

$8 c, 73 \%$

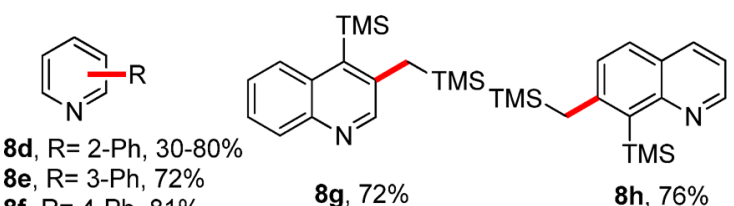

$8 \mathrm{e}, \mathrm{R}=3-\mathrm{Ph}, 72 \%$

8f, $\mathrm{R}=4-\mathrm{Ph}, 81 \%$

$8 g, 72 \%$

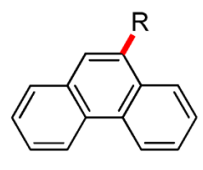

$8 \mathrm{j}, \mathrm{R}=\mathrm{Me}, 93 \%$

$8 k$, R=Vinyl, $55 \%$

nickel-catalyzed cross-coupling with amines, ${ }^{41}$ boroxines, ${ }^{42}$ aminoacetonitriles, ${ }^{43}$ arylsilanes, ${ }^{44}$ and polyfluorobenzenes (via $\mathrm{C}-\mathrm{H} / \mathrm{C}-\mathrm{O}$ cleavage) ${ }^{45}$ are summarized in Scheme 10.

Scheme 10. Cross-Coupling Reactions of Aryl Carbamates and Carbonates with Different Nucleophiles

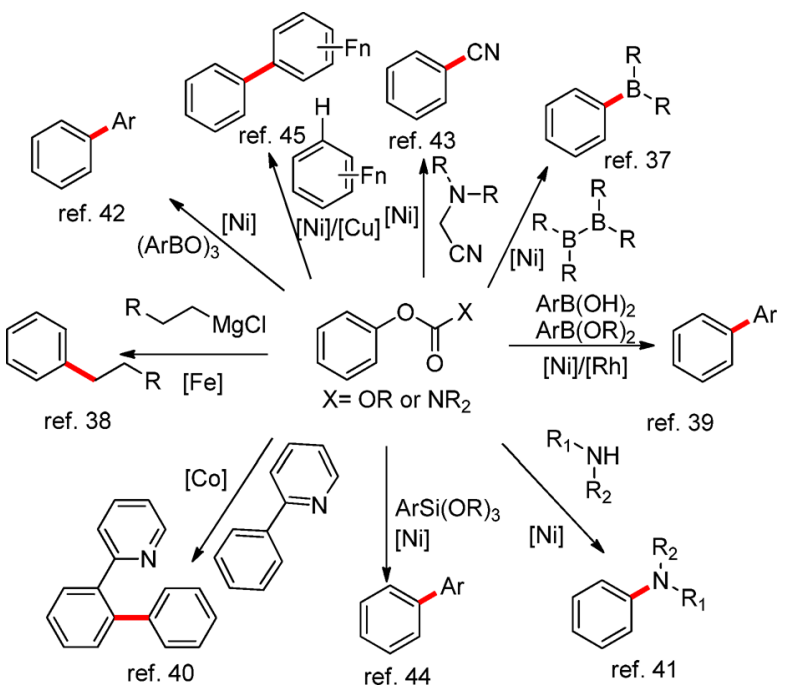

2.4. Cross-Coupling of Phenol Esters. In 2008, the first examples of cross-coupling using aryl pivalates catalyzed by nickel were reported independently, almost simultaneously, by the groups of $\mathrm{Shi}^{46}$ and $\mathrm{Garg}^{47}$ (Scheme 11). The pivalate and acetate derivatives of substituted naphthols and phenols were coupled effectively with phenylboroxines and phenylboronic reagents in good to high yields. Subsequently, Shi's group reported a nickel-catalyzed cross-coupling of aryl and alkenyl pivalates with organozinc reagents. ${ }^{48}$

In addition to the aforementioned examples, a variety of other nucleophiles have proven advantageous for crosscoupling reactions. Aryl carboxylates have been coupled 
Scheme 11. Cross-Coupling Reactions of Aryl Pivalates with Boroxines

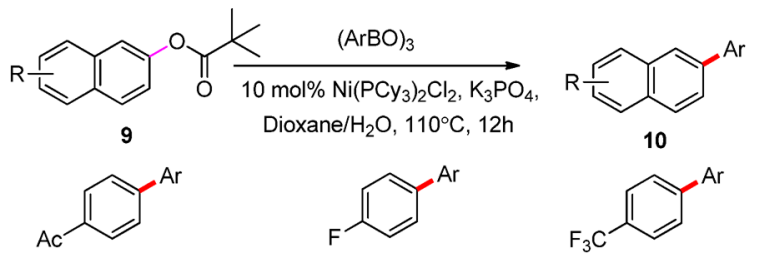

$10 \mathrm{a}, \mathrm{Ar}=4-\mathrm{MeOC}_{6} \mathrm{H}_{4}, 75 \%$ 10c, $\mathrm{Ar}=4-\mathrm{MeOC}_{6} \mathrm{H}_{4}, 68 \% 10 \mathrm{~d}, \mathrm{Ar}=4-\mathrm{MeOC}_{6} \mathrm{H}_{4}, 50 \%$ 10b, $\mathrm{Ar}=\mathrm{Ph}, 64 \%$

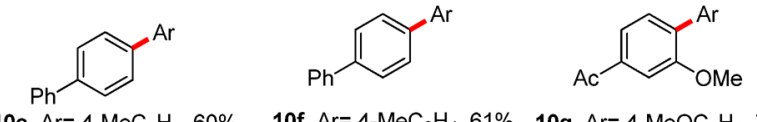

10e, $\mathrm{Ar}=4-\mathrm{MeC}_{6} \mathrm{H}_{4}, 60 \% \quad 10 \mathrm{f}, \mathrm{Ar}=4-\mathrm{MeC}_{6} \mathrm{H}_{4}, 61 \% \quad 10 \mathrm{~g}, \mathrm{Ar}=4-\mathrm{MeOC}_{6} \mathrm{H}_{4}, 72 \%$

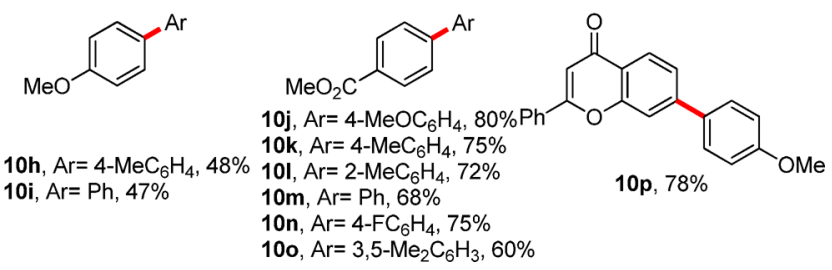

successfully with a wide range of nucleophilic partners including styrenes, ${ }^{49}$ ketones, ${ }^{50 a, b}$ esters and amides, ${ }^{50 c}$ silylboranes, ${ }^{51}$ carbon dioxide, ${ }^{52}$ secondary phosphine oxides, H-phosphinates, phosphonates and phosphines, ${ }^{53}$ alkylboron compounds, ${ }^{54}$ intramolecular $\mathrm{C}-\mathrm{O} / \mathrm{C}-\mathrm{H}$ cleavage, ${ }^{55}$ amines, ${ }^{56}$ intermolecular $\mathrm{C}-\mathrm{O} / \mathrm{C}-\mathrm{H}$ cleavage, ${ }^{57}$ and bis(neopentylglycolato)diboron $^{58}$ (Scheme 12).

Scheme 12. Cross-Coupling of Aryl Esters with Various Nucleophiles

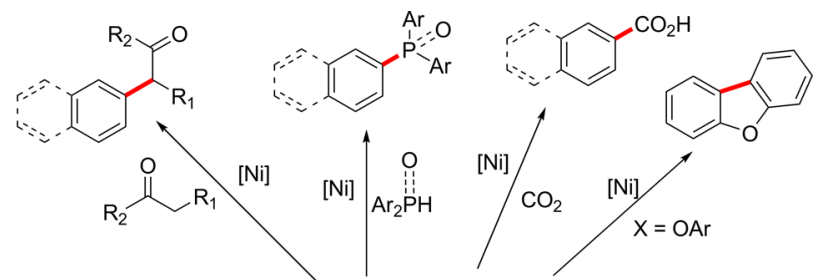

$\because \mathrm{ArZnCl}$

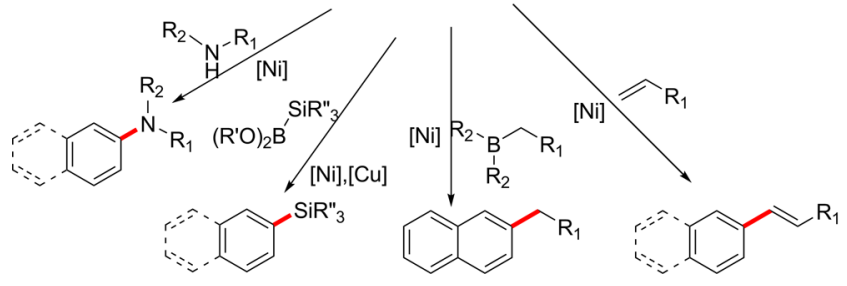

2.5. Cross-Coupling of Phenol Ethers. In 1979, Wenkert and co-workers reported the pioneering work of transforming enol and aryl ethers into olefins and biaryls, respectively. Crosscoupling of enol ethers with aromatic Grignard reagents proceeded effectively using nickel catalysis (Scheme 13). ${ }^{59}$ Unfortunately, synthetically useful yields of the desired biaryl products were limited to the more reactive 1 - and 2methoxynaphthalene derivatives. Almost 30 years later, Dankwardt's group optimized this reaction. When using $\mathrm{PCy}_{3}$ as a ligand and glyme as a solvent they achieved moderate to excellent yields of the cross-coupling products (Scheme 14). ${ }^{60}$
Scheme 13. Cross-Coupling Reactions of Aryl and Enol Ethers with Grignard Reagents

$$
\text { Benzene, reflux, 15-48h }
$$

Scheme 14. Improved Cross-Coupling of Aryl Ethers with Grignard Reagents

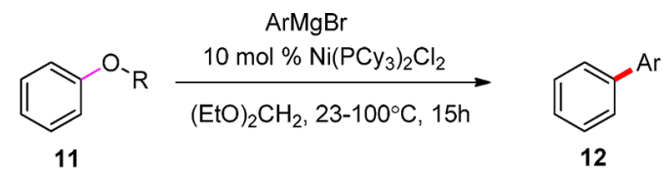

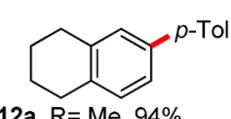

12a, $R=M e, 94 \%$

12b, R= MOM, $77 \%$

12c, $R=T M S, 70 \%$

12d, $\mathrm{R}=\left(\mathrm{CH}_{2}\right)_{2} \mathrm{OMe}, 77 \%$

12e, $\mathrm{R}=\left(\mathrm{CH}_{2}\right)_{2} \mathrm{NMe}_{2}, 99 \%$

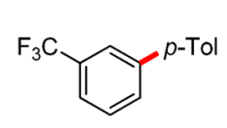

12k, $\mathrm{R}=\mathrm{Me}, 61 \%$

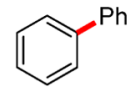

12f, $R=E t, 73 \%$ 12g, $\mathrm{R}=\mathrm{CF}_{3}, 30 \%$ 12h, R= TMS, $72 \%$<smiles>C1=C(N2CCCCC2)c2ccc(-c3ccccc3)cc2CC1</smiles>

12j, $R=M e, 58 \%$ 12i, $\mathrm{R}=\left(\mathrm{CH}_{2}\right)_{2} \mathrm{OH}, 67 \%$<smiles>OC(c1ccccc1)c1ccc(P)cc1</smiles>

12I, $\mathrm{R}=\mathrm{Me}, 61 \%$<smiles>CN(C)Cc1cccc(O[Ga])c1</smiles>

$12 \mathrm{~m}, \mathrm{R}=\mathrm{Me}, 73 \%$<smiles>Oc1ccc(-c2cccc([Se][Te])c2)cc1</smiles>
$12 n, R=M e, 63 \% \quad 12 o, R=M e, 75 \% \quad 12 p, R=M e, 54 \% 12 q, R=M e, 73 \%$<smiles>CNCCn1ccc2cccc([GaH2])c21</smiles>

$12 r, R=M e, 55 \%$<smiles>c1ccc(-c2ccc(C(c3ccccc3)n3ccnc3)cc2)cc1</smiles>

12s, $\mathrm{R}=\mathrm{Me}, 74 \%$

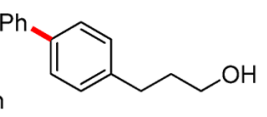

12t, $\mathrm{R}=\mathrm{Me}, 77 \%$
The method can tolerate a wide range of functional groups on the aryl ether, such as alcohols, phenols, amines, enamines, and $\mathrm{N}$-heterocycles. Various biaryl compounds can be synthesized by this method. Many studies have emerged since with respect to the coupling of aromatic alkyl ethers with different nucleophiles via $\mathrm{C}-\mathrm{O}$ bond cleavage (Scheme 15). These include couplings with boronic esters, ${ }^{61}$ alkyl Grignard reagents, ${ }^{62}$ amines, ${ }^{63}$ organozinc reagents, ${ }^{64}$ lithium reagents, ${ }^{65}$ boron reagents, ${ }^{66}$ alkynyl Grignard reagents, ${ }^{67}$ alkyl aluminum reagents, ${ }^{68}$ and homocoupling. ${ }^{69}$

Although nickel-catalyzed processes predominate for $\mathrm{C}-\mathrm{O}$ bond cleavage of aromatic alkyl ethers, ruthenium- and chromium-catalyzed variants have also been reported but generally require a directing group at the ortho-position (Scheme 16). In 2004, Kakiuchi's group reported a chelationassisted, ruthenium-catalyzed cross-coupling of aromatic ethers with organoboron compounds via $\mathrm{C}-\mathrm{O}$ bond cleavage. ${ }^{70}$ Boronic esters can be coupled with aromatic alkyl ethers through amide-assisted chelation, as reported by Snieckus's group in $2014 .^{71}$ Furthermore, in 2015, Zeng's group reported a related cross-coupling reaction with Grignard reagents through imine chelation. ${ }^{72}$

Iranpoor's group reported a nickel-catalyzed formal direct amination of phenols via $\mathrm{C}-\mathrm{O}$ bond activation using 2,4,6trichloro-1,3,5-triazine (TCT) as the activating reagent (Scheme 17). ${ }^{73}$ In this process, phenols were first transformed 
Scheme 15. Cross-Coupling of Aryl Ethers with Different Nucleophiles

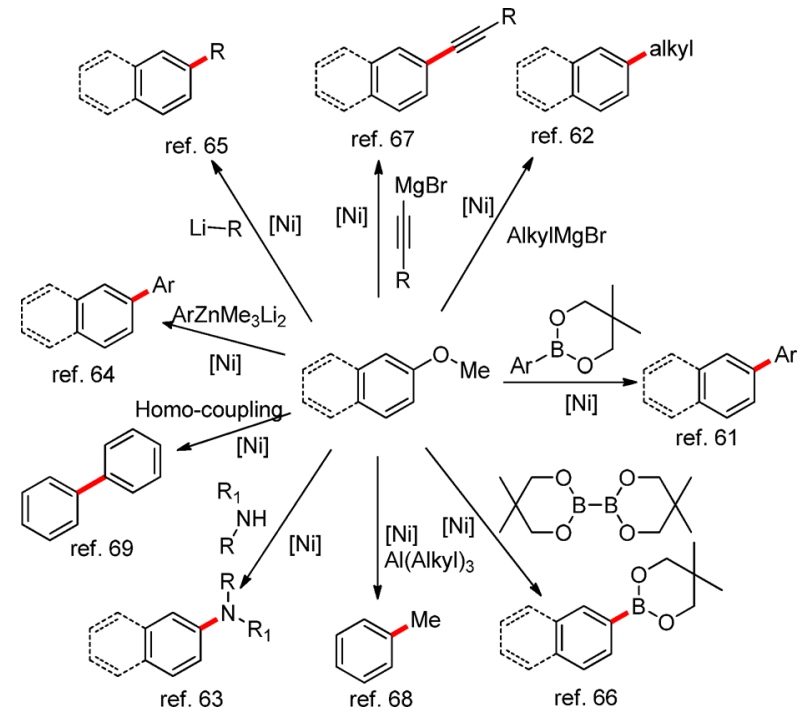

Scheme 16. Ortho-Directed Cross-Coupling of Aryl Ethers with Different Nucleophiles via $\mathrm{C}-\mathrm{O}$ Activation

$$
\begin{aligned}
& \text { t-Bu }-\mathrm{N}_{\mathrm{ArMgCl}}^{\mathrm{C}}
\end{aligned}
$$

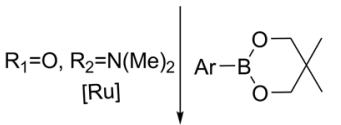

$$
\begin{aligned}
& \text { Me- }
\end{aligned}
$$

into aromatic ether intermediates, which were then coupled with amines via nickel-catalyzed cleavage of the $\mathrm{C}-\mathrm{O}$ bond.

Scheme 17. Formal Cross-Coupling Reactions of Phenols with Amines

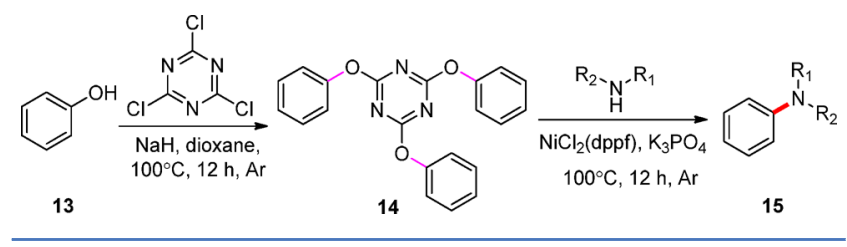

2.6. Cross-Coupling of Phenolic Salts. Because phenols have a reactive, acidic hydroxyl group, they are prevented from reacting with nucleophiles during catalytic processes. One approach to overcome this challenge is to transform phenols into the corresponding phenolic salt. Shi's group reported the first example of such a cross-coupling reaction using magnesium 2-naphthalenolate with Grignard reagents to construct biaryl scaffolds (Scheme 18). ${ }^{74}$ Subsequently, the same group went on to report the cross-coupling of sodium 2naphthalenolate with arylboroxine via direct cleavage of the $\mathrm{C}-$ O bond (Scheme 19). ${ }^{75}$ However, only one simple phenol derivative was obtained in low yield. Thus, further investigation is necessary for the development of this reaction.
Scheme 18. Cross-Coupling of Phenolic Salts with Grignard Reagents

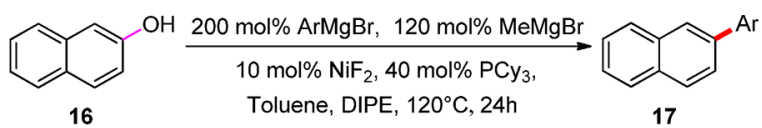

Toluene, DIPE, $120^{\circ} \mathrm{C}, 24 \mathrm{~h}$

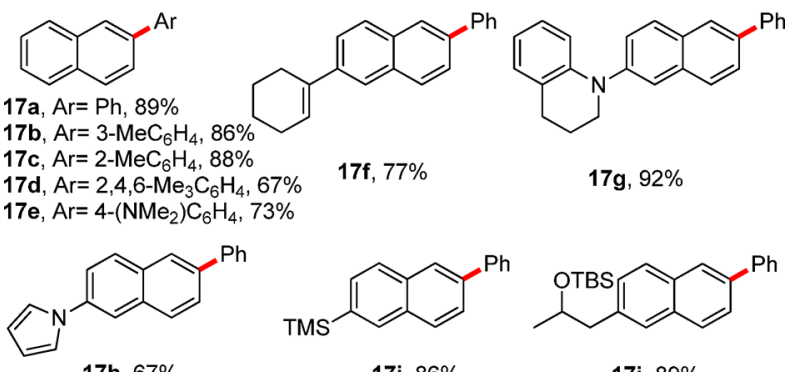

$17 \mathrm{~h}, 67 \%$

$17 i, 86 \%$

$17 \mathrm{j}, 89 \%$

Scheme 19. Cross-Coupling of Aryl Salts with Boronic Esters

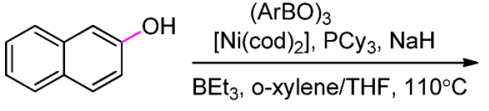

18

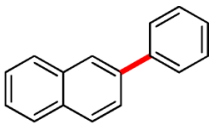

19
An elegant example of harnessing the reactivity differences between aryl tosylates, pivalates, and methyl ethers in synthesis via selective $\mathrm{C}-\mathrm{O}$ bond activations is shown in Scheme 20. ${ }^{54}$

Scheme 20. An Example Illustrating the Reactivity Difference among Different $\mathrm{C}-\mathrm{O}$ Bonds
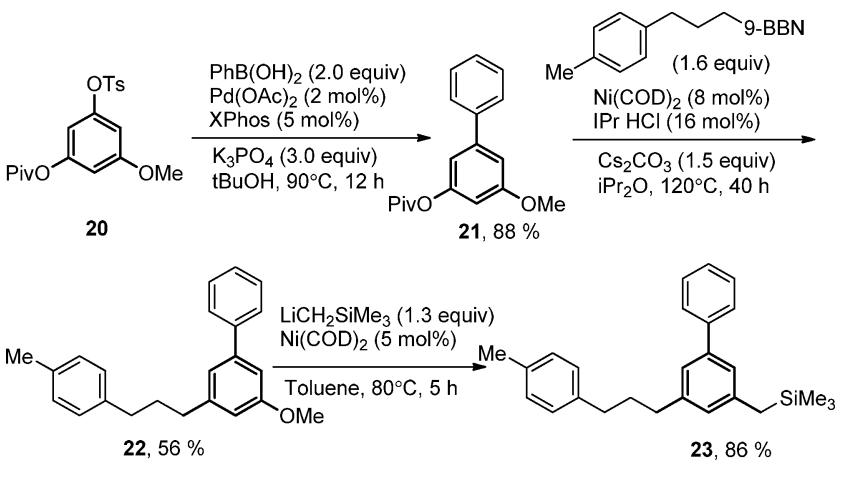

First, the highly reactive tosylate $\mathrm{C}-\mathrm{O}$ bond was coupled with a boronic acid under palladium-catalyzed, Suzuki-Miyaura crosscoupling conditions; this was followed by a nickel-catalyzed cross-coupling of the less reactive pivalate $\mathrm{C}-\mathrm{O}$ bond; while the least reactive methyl ether $\mathrm{C}-\mathrm{O}$ bond was cross-coupled with a lithium reagent catalyzed by nickel.

Undoubtedly, the development of a direct cross-coupling reaction with no prior activation of phenols would be highly desirable due to convenience, reduced costs and waste generation, and improved step-economy. Efforts toward this aim are summarized in the following section.

\section{DIRECT CROSS-COUPLING OF PHENOLS}

3.1. Direct Cross-Coupling of Phenols in Gas Phase. Reactions in the gas phase using phenols have been mostly developed for amminolysis. However, some efforts toward thiolation reactions have also been reported. Reactions often proceed in continuous flow reactors capable of handling high 
temperatures and pressures. A summary of relevant gas-phase cross-couplings of phenol is presented below.

The first process for the amination of phenol in the gas phase was published in 1966 by the Halcon International Inc. ${ }^{76}$ Previously, aniline had been synthetically prepared by nitration of benzene, followed by reduction of the nitro moiety over various metal catalysts. ${ }^{77}$ The reaction is reported to take place in the presence of ammonia when using one of the following Lewis-acidic catalysts: $\mathrm{SiO}_{2}-\mathrm{Al}_{2} \mathrm{O}_{3}, \mathrm{TiO}_{2}-\mathrm{Al}_{2} \mathrm{O}_{3}, \mathrm{ZrO}_{2}-\mathrm{Al}_{2} \mathrm{O}_{3}$, $\mathrm{H}_{3} \mathrm{PO}_{4}$ or $\mathrm{WO}_{3}$. The reaction is in equilibrium and is pushed to the aniline products by using high ammonia concentrations, temperatures between 350 and $500{ }^{\circ} \mathrm{C}$ and high pressures. Catalysts require regeneration afterward due to the formation of carbonaceous deposits and is facilitated by incorporating metals or metal oxides from cerium, vanadium, or tungsten into the catalyst. Conversions and reaction yields for certain phenolic compounds under the reported conditions are summarized in Table 1 . Phenol is first vaporized, mixed with

Table 1. Amination of Phenols

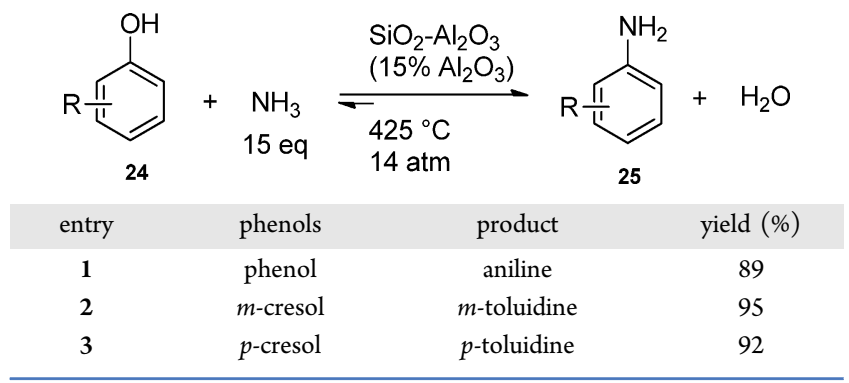

fresh and recycled ammonia, and then fed into the reactor containing the catalyst at the indicated temperature. Gas products leaving the reactor are cooled down and purified by distillation. $^{78}$

Byproducts of the reaction include $1-2 \mathrm{~mol} \%$ of diphenylamine and $0.1 \mathrm{~mol} \%$ of carbazoles. The constitution of the $\mathrm{SiO}_{2}-\mathrm{Al}_{2} \mathrm{O}_{3}$ catalyst plays an important role, as it becomes more strongly acidic when the amount of $\mathrm{Al}_{2} \mathrm{O}_{3}$ present is between $10-20$ wt \%, which increases product yields. When the reaction temperature was decreased to 350 ${ }^{\circ} \mathrm{C}$, the yield dropped to less than $25 \%$, highlighting the temperature dependence of the reaction. Using $\mathrm{TiO}_{2}-\mathrm{Al}_{2} \mathrm{O}_{3}$ gives similar results as those shown in entry 1 , while $\gamma-\mathrm{Al}_{2} \mathrm{O}_{3}$ only gave a $45 \%$ yield of aniline even when the temperature is increased to $475{ }^{\circ} \mathrm{C}$. The process was industrialized with the first plant being opened in Japan in $1970,{ }^{79}$ producing $20000 \mathrm{t}$ of aniline per year, followed by a second plant in the United States in $1980 .^{78}$ In 1975 , Halcon published a different type of $\mathrm{Al}_{2} \mathrm{O}_{3}$ catalyst system for the ammonolysis of phenol, consisting of alumina derived from a precipitated gel form containing less than $1.0 \mathrm{wt} \%$ of an alkali metal. ${ }^{80}$ Using this method, the operational temperature required was decreased from 425 to $365{ }^{\circ} \mathrm{C}$. Conversion was reported to be $>99 \%$ with a $99 \%$ selectivity for aniline, a wide range of phenolic compounds can be used in the reaction.

In 1981, Ono and Ishida published the first amination of phenol using palladium supported on alumina as the catalyst. ${ }^{81}$ The reaction was developed guided by the hypothesis that hydrogenation of phenol gives cyclohexanone using an effective hydrogenation catalyst, and subsequent attack on the ketone by an amine would give the aminated product. Moving from traditional acidic catalysts used by industry to a palladium catalyst allowed the reaction to take place at lower temperatures than those previously reported. The best reaction conditions and proposed reaction mechanism are shown in Scheme 21.

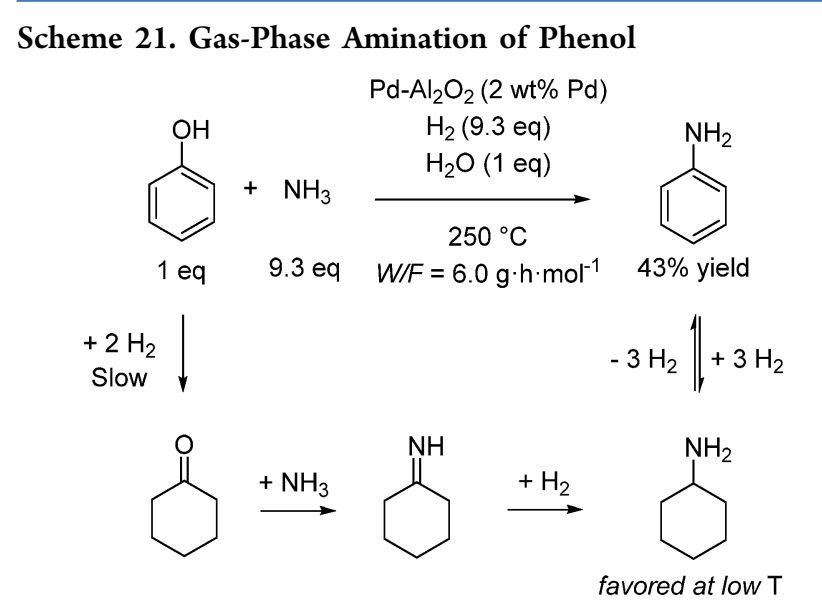

The reaction rate is first order with respect to the partial pressure of hydrogen below $0.3 \mathrm{~atm}$ and does not depend on the partial pressure of ammonia between 0.15 and $0.45 \mathrm{~atm}$, indicating that the rate-determining step corresponds to the hydrogenation of phenol to cyclohexanone.

Several metals were tested for the transformation under the standard reaction conditions using a $0.5 \mathrm{wt} \%$ loading of the catalyst. Metals tested included $\mathrm{Pd}, \mathrm{Pt}, \mathrm{Rh}, \mathrm{Ru}, \mathrm{Cu}, \mathrm{Co}, \mathrm{Ni}$, and Fe. Palladium was shown to be the best catalyst, giving a selectivity of $70 \%$ and an aniline yield of $30 \%$. Platinum and rhodium worked moderately, giving aniline yields of $28 \%$ and $10 \%$, respectively. The other metals showed no activity for the desired transformation. With regards to the solid support used, the following activity order was reported, and the number in parentheses indicates aniline yield:

$$
\begin{gathered}
\mathrm{Al}_{2} \mathrm{O}_{3}(44 \%)>\text { carbon }(12 \%)>\mathrm{SiO}_{2}(3 \%) \\
>\mathrm{SiO}_{2}-\mathrm{Al}_{2} \mathrm{O}_{3}(2 \%)>\text { Y-zeolite }(0 \%)
\end{gathered}
$$

Product formation was only observed when hydrogen was present in the reaction. Reaction selectivity was dependent on the temperature; aniline forms at temperatures above $230{ }^{\circ} \mathrm{C}$. Lower temperatures $\left(140-200{ }^{\circ} \mathrm{C}\right)$ gave dicyclohexylamine and cyclohexylamine as the main products, whereas temperatures above $250{ }^{\circ} \mathrm{C}$ favored phenol hydrocracking and the aldolic condensation of cyclohexanone. Other phenolic compounds were also tested for the reaction and the product yield decreased in the following order: phenol $>o$-cresol $>m$ cresol $>p$-cresol $>2$,4-dimethylaniline. These results are in accordance with the ease of hydrogenation of the corresponding aromatic compounds. The activity of the palladium catalyst was further improved by making an alloy with gold, attributed to better palladium dispersion in the reaction. When using $\mathrm{Pd}-$ $\mathrm{Au}-\mathrm{Al}_{2} \mathrm{O}_{3}$ as the catalyst, aniline was obtained in $50 \%$ yield with $60 \%$ selectivity and conversion. This catalyst also proved to be more stable over a longer period.

Chang and co-workers reported in 1983 the first phenol ammonolysis using ZSM-5 type zeolites. ${ }^{82}$ This procedure improved the Halcon process by suppressing or eliminating byproducts such as diphenylamine and carbazole. This was attributed to the shape selectivity of the zeolite itself. Although the conversion is reported to be as high as $92.4 \%$ with a 
selectivity for aniline of $99.6 \%$, the only specific example provided (Scheme 22 ) generated $3 \%$ of byproducts in addition

Scheme 22. Ammonolysis of Phenol

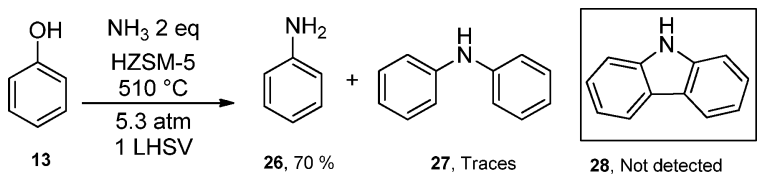

to the desired product. A subsequent publication during the same year provided a more detailed analysis of the other byproducts, showing that 2-methylpyridine was the main impurity formed. ${ }^{83}$ Some advantages of using ZSM-5 type zeolites include the fact that they are capable of retaining their crystallinity for long periods of time despite high temperatures. Additionally, they possess a very low coke-forming capability, which allows for long usage periods before catalyst regeneration is necessary.

In 1991, the Mitsui Petrochemical Industries used mildly acidic $\gamma$-alumina catalysts $\left(\mathrm{p} K_{\mathrm{a}}=3.3\right.$ to 6.8$)$ to successfully aminate phenolic compounds at $380{ }^{\circ} \mathrm{C}$ with a phenol conversion of $99.8 \%$ and an aniline selectivity of $98.9 \% .{ }^{84}$ Activity of the catalyst was maintained after 180 days of continuous process. Other catalysts patented for the ammonolysis of phenol include niobium catalysts on alumina $\left(\mathrm{Al}_{2} \mathrm{O}_{3}-\mathrm{Nb}_{2} \mathrm{O}_{5}\right)$ that give a $96 \%$ yield of aniline at $380{ }^{\circ} \mathrm{C} .{ }^{85} \mathrm{In}$ 2005, a catalyst containing Pd (0.5 wt \%)-La (0.1 wt \%)$\mathrm{Al}_{2} \mathrm{O}_{3}$ was reported to facilitate the amination of 2,6diisopropylphenol at $220{ }^{\circ} \mathrm{C}$ and $25 \mathrm{~atm}$; the corresponding aminated product was obtained in $83.8 \%$ yield. ${ }^{86}$ Finally, bentonite-based palladium-catalysts were patented in 2013, which can facilitate the reaction at temperatures below 210 ${ }^{\circ} \mathrm{C} .{ }^{87}$

The first patent describing the thiolation of alcohols and ethers was published in $1962 .{ }^{88}$ The described process transformed aliphatic starting materials into thiolated products in good to moderate yields. However, when the reaction was attempted using aromatic alcohols, only low yields of the desired products were observed (Table 2, entry 1 ).

Table 2. Thiolation of Phenol

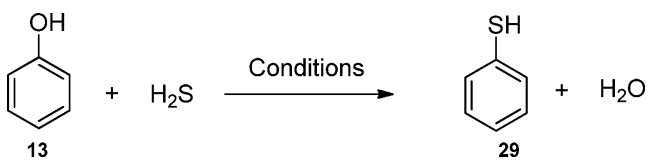

\begin{tabular}{clcc} 
entry & \multicolumn{1}{c}{ catalysts } & temperature $\left({ }^{\circ} \mathrm{C}\right)$ & yield (\%) \\
$\mathbf{1}$ & $2 \% \mathrm{~K}_{3} \mathrm{PO}_{4}\left(\mathrm{WO}_{3}\right)_{12}$ on $\mathrm{Al}_{2} \mathrm{O}_{3}$ & 350 & 15 \\
$\mathbf{2}$ & $\mathrm{SiO}_{2}$ & 400 & 20 \\
3 & $\mathrm{TiO}_{2}-\mathrm{ZrO}_{2}\left(40 \mathrm{Wt} \% \mathrm{TiO}_{2}\right)$ & 500 & 86 \\
\hline
\end{tabular}

A second patent published in 1980 converted phenols or naphthols into their respective aromatic thiols with hydrogen sulfide, at temperatures ranging from 400 to $600{ }^{\circ} \mathrm{C}$, using $\mathrm{SiO}_{2}$ or $\mathrm{TiO}_{2}$ catalysts (Table 2, entry 2). ${ }^{89}$ Phenol conversion was equal to $50 \%$, and some of the byproducts observed included diphenyl sulfide and diphenyl disulfide.

In 2011, the thiolation of phenol was reported to occur with excess hydrogen sulfide (2-10 equiv) in the presence of a composite metal oxide. Best conditions were obtained with $\mathrm{TiO}_{2}-\mathrm{ZrO}_{2}$ with a $\mathrm{TiO}_{2}$ content of 30 to $60 \mathrm{~mol} \% .{ }^{90}$ When using $\mathrm{ZrO}_{2}-\mathrm{TiO}_{2}$ as the catalyst at $500{ }^{\circ} \mathrm{C}$, thiophenol was obtained in $86 \%$ yield with an $88 \%$ conversion (Table 2, entry 3).

3.2. Direct Cross-Coupling of Phenols in Liquid Phase. The gas phase cross-coupling of phenols usually requires high temperatures $\left(>250{ }^{\circ} \mathrm{C}\right)$, a carefully designed heterogeneous catalyst, and special operational equipment. Furthermore, the scope is mostly limited to simple phenols and to the ammonolysis reaction.

The earliest example of phenol cross-coupling in the liquid phase was reported by the Wakabayashi group in 1985 (Scheme 23). ${ }^{91}$ By employing cyclohexanol as the hydrogen transfer

Scheme 23. Early Example of Phenol Cross-Coupling in the Liquid Phase

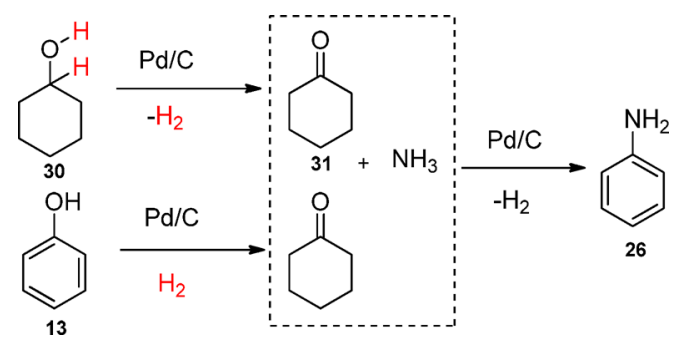

reagent, phenol and cyclohexanol can be coaminated to cyclohexylamine using ammonia, followed by further dehydrogenation to aniline over $\mathrm{Pd} / \mathrm{C}$. However, this transformation still requires high temperatures $\left(250{ }^{\circ} \mathrm{C}\right)$, and the reaction scope is limited to phenol (due to the requirement of cyclohexanol) and ammonia.

In 2012, our group developed a catalytic oxidative/ dehydrogenative aromatization process to construct $\mathrm{C}-\mathrm{O}$ and $\mathrm{C}-\mathrm{N}$ bonds catalyzed by $\mathrm{Cu}$ or $\mathrm{Pd}$ in the presence of oxygen (Scheme 24). ${ }^{92}$ In this process, cyclohexanone or cyclohexenone condenses with alcohols or amines in situ, followed by further dehydrogenation to form aromatic ethers or anilines.

Scheme 24. Oxidative Catalytic Dehydrogenative Aromatization

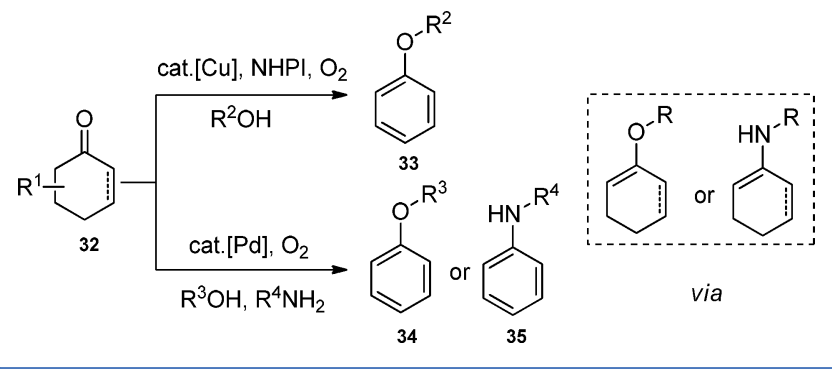

One year later, in 2013, the Lemaire group reported an alternative $\mathrm{Pd} / \mathrm{C}$-catalyzed dehydrogenative aromatization reaction to generate aryl ethers or amines under neat (solvent free) conditions (Scheme 25). ${ }^{93}$ By employing a hydrogen

Scheme 25. Pd/C-Catalyzed Dehydrogenative Aromatization

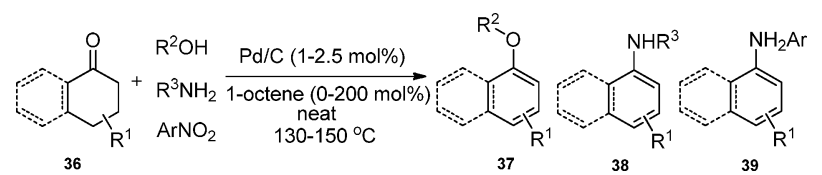


acceptor, such as 1-octenene, a nitroarene, or oxygen (open air reaction), the reaction proceeds with high efficiency. It is worth noting that the reaction can also be run under argon without a hydrogen acceptor, but a temperature of $150{ }^{\circ} \mathrm{C}$ is required and lower yields are obtained. Notable related studies have also been reported by Deng, Yoshikai, and Stahl. ${ }^{94}$

In 2015, our group developed a mild and highly efficient method to directly couple phenol with amines using sodium formate as the hydride source and $\mathrm{Pd} / \mathrm{C}$ as the catalyst in the presence of catalytic amounts of TFA. This transformation proceeded through a catalytic reductive dearomatizationcondensation-rearomatization (or "hydrogen-borrowing") strategy (Scheme 26). ${ }^{95}$ The reaction tolerates a broad scope

\section{Scheme 26. Direct Cross-Coupling of Phenols with Amines}

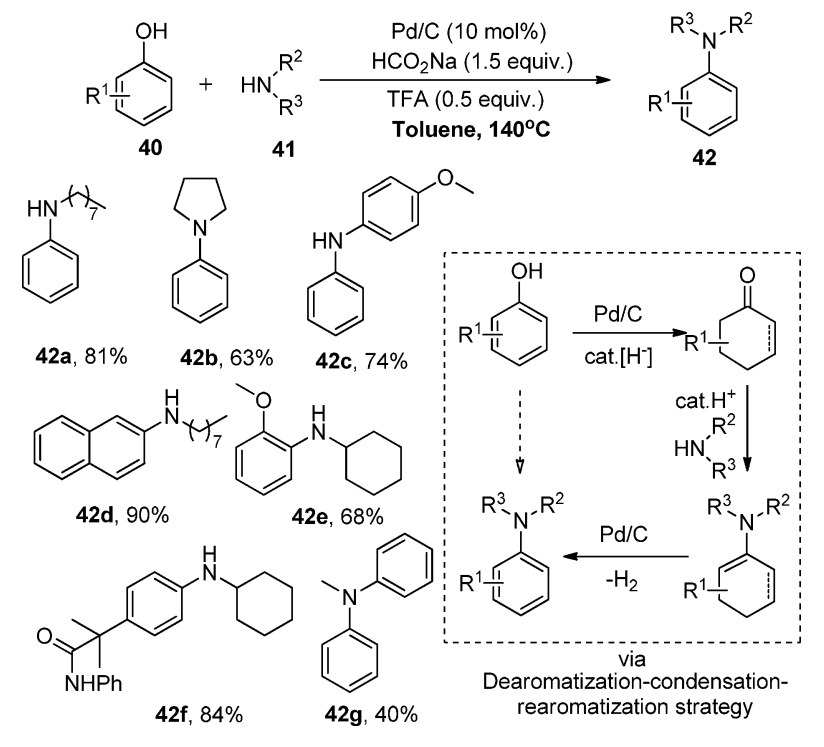

of phenols, catechols, and naphthols with primary, secondary, aliphatic, and aromatic amines as nucleophiles. When the quantity of sodium formate was increased to 6 equiv, cyclohexylamines were obtained in high yields, ${ }^{96}$ and in a later study, the reaction was successfully carried out in a flow reactor. ${ }^{97}$

In 2016, a transition-metal-free oxidative dearomatizationcondensation-rearomatization process to synthesize aniline was reported by the Alaniz group (Scheme 27). ${ }^{98}$ A "one-pottwo-step" method was applied in this reaction, in which the phenol was first oxidatively dearomatized by a stoichiometric

\section{Scheme 27. Oxidative Dearomatization Process to} Synthesize Aniline

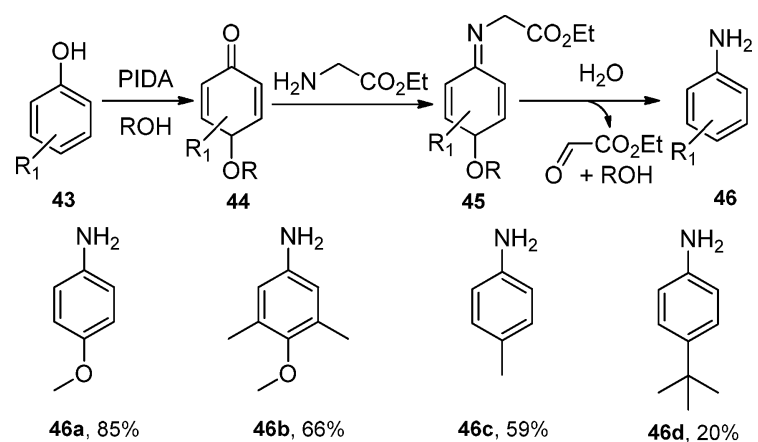

quantiny of PIDA, then condensed with glycine ethyl ester and further rearomatized to form aniline. The reaction worked well with electron rich phenols and gram scale syntheses can achieved. In addition, the reduction (deoxygenation) of phenols using nickel catalysis was also reported by Shi and Nakao. ${ }^{99}$

\section{CONCLUSIONS AND OUTLOOK}

In conclusion, we have explored the cross-coupling of phenol derivatives and phenols with different nucleophiles via $\mathrm{C}-\mathrm{O}$ bond cleavage. In order to find more sustainable alternatives to aryl halides, significant developments have been made toward using phenol derivatives (e.g., sulfonates, carbamates, carbonates, phosphates, esters, ethers, and metal salts) and phenols for cross-coupling reactions. Although some recent advances have been made in the direct cross-coupling of phenols with amines, further studies are needed to develop the direct coupling of phenols with a wide range of coupling partners. Exciting developments in this field can be expected in the near future.

\section{AUTHOR INFORMATION}

\section{Corresponding Authors}

*E-mail: zenghy@lzu.edu.cn.

*E-mail: cj.li@mcgill.ca.

ORCID ${ }^{\circ}$

Chao-Jun Li: 0000-0002-3859-8824

\section{Author Contributions}

${ }^{\#}$ These authors contributed equally (Z.Q. and A.D.-H.).

Notes

The authors declare no competing financial interest.

\section{ACKNOWLEDGMENTS}

We thank the Recruitment Program of Global Experts and the National Science Foundation of China (No. 21302073), the Fundamental Research Funds for the Central Universities (lzujbky-2016-53) and Lanzhou University, as well as the Canada Research Chair (Tier I) foundation, the E.B. Eddy endowment fund, the CFI, NSERC, and FQRNT for support of our research.

\section{REFERENCES}

(1) (a) Hassan, J.; Sevignon, M.; Gozzi, C.; Schulz, E.; Lemaire, M. Chem. Rev. 2002, 102, 1359-1470. (b) Stanforth, S. P. Tetrahedron 1998, 54, 263-303. (c) Brown, B. R. The Organic Chemistry of Aliphatic Nitrogen Compounds; Cambridge University: Cambridge, 2004. (d) McElroy, W. T.; DeShong, P. Tetrahedron 2006, 62, 69456954. (e) Torres, J. C.; Pinto, A. C.; Garden, S. J. Tetrahedron 2004, 60, 9889-9900. (f) Lawerence, S. A. Amines: Synthesis, Properties and Applications; Cambridge University: Cambridge, 2004. (g) Hajduk, P. J.; Bures, M.; Praestgaard, J.; Fesik, S. W. J. Med. Chem. 2000, 43, 3443-3447.

(2) (a) Metal-Catalyzed Cross-Coupling Reactions; Diederich, F., Stang, P. J., Eds.; Wiley-VCH: Weinheim, Germany, 1998. (b) CrossCoupling Reactions. A Practical Guide; Miyaura, N., Ed.; SpringerVerlag: Berlin, 2002. (c) Metal-Catalyzed Cross-Coupling Reactions; de Meijere, A., Diederich, F., Eds.; Wiley-VCH: Weinheim, Germany, 2004.

(3) For selected reviews, see: (a) Mesganaw, T.; Garg, N. K. Org. Process Res. Dev. 2013, 17, 29-39. (b) Yamaguchi, J.; Muto, K.; Itami, K. Eur. J. Org. Chem. 2013, 2013, 19-30. (c) Correa, A.; Cornella, J.; Martin, R. Angew. Chem., Int. Ed. 2013, 52, 1878-1880. (d) Tobisu, M.; Chatani, N. Top. Organomet. Chem. 2012, 44, 35-49. (e) Rosen, B. M.; Quasdorf, K. W.; Wilson, D. A.; Zhang, N.; Resmerita, A.-M.; Garg, N. K.; Percec, V. Chem. Rev. 2011, 111, 1346-1416. (f) Li, B.-J.; 
Yu, D.-G.; Sun, C.-L.; Shi, Z.-J. Chem. - Eur. J. 2011, 17, 1728-1759. (g) Yu, D.-G.; Li, B.-J.; Shi, Z.-J. Acc. Chem. Res. 2010, 43, 1486-1495. (h) Cornella, J.; Zarate, C.; Martin, R. Chem. Soc. Rev. 2014, 43, 80818097. (i) Tobisu, M.; Chatani, N. Acc. Chem. Res. 2015, 48, 17171726. (j) Tasker, S. Z.; Standley, E. A.; Jamison, T. F. Nature 2014, 509, 299-309.

(4) Heck, R. F. J. Am. Chem. Soc. 1968, 90, 5518-5526.

(5) (a) Paul, F.; Patt, J.; Hartwig, J. F. J. Am. Chem. Soc. 1994, 116, 5969-5970. (b) Guram, A. S.; Buchwald, S. L. J. Am. Chem. Soc. 1994, 116, 7901-7902.

(6) (a) Hatanaka, Y.; Fukushima, S.; Hiyama, T. Heterocycles 1990, 30, 303-308. (b) Hiyama, T.; Hatanaka, Y. Pure Appl. Chem. 1994, 66, 1471-1478. (c) Matsuhashi, H.; Kuroboshi, M.; Hatanaka, Y.; Hiyama, T. Tetrahedron Lett. 1994, 35, 6507-6510.

(7) Tamao, K.; Sumitani, K.; Kiso, Y.; Zembayashi, M.; Fujioka, A.; Kodama, S.-I.; Nakajima, I.; Minato, A.; Kumada, M. Bull. Chem. Soc. Jpn. 1976, 49, 1958-1969.

(8) Ullmann, F.; Bielecki, J. Ber. Dtsch. Chem. Ges. 1901, 34, 21742181.

(9) (a) Negishi, E.-I.; Baba, S. J. Chem. Soc., Chem. Commun. 1976, 596b-597. (b) Negishi, E.-I.; King, A. O.; Okukado, N. J. Org. Chem. 1977, 42, 1821-1823.

(10) Sonogashira, K.; Tohda, Y.; Hagihara, N. Tetrahedron Lett. 1975, 16, 4467-4470.

(11) Milstein, D.; Stille, J. K. J. Am. Chem. Soc. 1978, 100, 36363638.

(12) (a) Miyaura, N.; Yamada, K.; Suzuki, A. Tetrahedron Lett. 1979, 20, 3437-3440. (b) Miyaura, N.; Suzuki, A. J. Chem. Soc., Chem. Commun. 1979, 866-867. (c) Ishiyama, T.; Murata, M.; Miyaura, N. J. Org. Chem. 1995, 60, 7508-7510.

(13) Leowanawat, P.; Zhang, N.; Percec, V. J. Org. Chem. 2012, 77, $1018-1025$.

(14) Badone, D.; Cecchi, R.; Guzzi, U. J. Org. Chem. 1992, 57, 63216323.

(15) Percec, V.; Bae, J.-Y.; Zhao, M.; Hill, D. H. J. Org. Chem. 1995, 60, 176-185.

(16) (a) Roy, A. H.; Hartwig, J. F. J. Am. Chem. Soc. 2003, 125, 8704-8705. (b) Cho, C.-H.; Yun, H.-S.; Park, K. J. Org. Chem. 2003, $68,3017-3025$.

(17) (a) Furstner, A.; Leitner, A.; Mendez, M.; Krause, H. J. Am. Chem. Soc. 2002, 124, 13856-13863. (b) Furstner, A.; Leitner, A. Angew. Chem., Int. Ed. 2002, 41, 609-612.

(18) (a) Hamann, B. C.; Hartwig, J. F. J. Am. Chem. Soc. 1998, 120, 7369-7370. (b) Kawatsura, M.; Hartwig, J. F. J. Am. Chem. Soc. 1999, 121, 1473-1478. (c) Huang, X.; Anderson, K. W.; Zim, D.; Jiang, L.; Klapars, A.; Buchwald, S. L. J. Am. Chem. Soc. 2003, 125, 6653-6655. (d) Ramgren, S. D.; Silberstein, A. L.; Yang, Y.; Garg, N. K. Angew. Chem., Int. Ed. 2011, 50, 2171-2173. (e) Alsabeh, P. G.; Stradiotto, M. Angew. Chem., Int. Ed. 2013, 52, 7242-7246.

(19) (a) Nguyen, H. N.; Huang, X.; Buchwald, S. L. J. Am. Chem. Soc. 2003, 125, 11818-11819. (b) Percec, V.; Bae, J.-Y.; Hill, D. H. J. Org. Chem. 1995, 60, 1060-1065. (c) Ueda, M.; Saitoh, A.; Ohtani, S.; Miyaura, N. Tetrahedron 1998, 54, 13079-13086. (d) Huffman, M. A.; Yasuda, N. Synlett 1999, 1999, 471-473.

(20) Gelman, D.; Buchwald, S. L. Angew. Chem., Int. Ed. 2003, 42, 5993-5996.

(21) Zhang, L.; Meng, T.; Wu, J. J. Org. Chem. 2007, 72, 9346-9349.

(22) Kobayashi, Y.; Mizojiri, R. Tetrahedron Lett. 1996, 37, 85318534.

(23) Munday, R. H.; Martinelli, J. R.; Buchwald, S. L. J. Am. Chem. Soc. 2008, 130, 2754-2755.

(24) Schade, M. A.; Metzger, A.; Hug, S.; Knochel, P. Chem. Commun. 2008, 3046-3048.

(25) Zhang, L.; Wu, J. J. Am. Chem. Soc. 2008, 130, 12250-12251.

(26) Gooßen, L. J.; Rodriguez, N.; Lange, P. P.; Linder, C. Angew. Chem., Int. Ed. 2010, 49, 1111-1114.

(27) Bolm, C.; Hildebrand, J. P.; Rudolph, J. Synthesis 2000, 2000, 911-913.
(28) (a) Ackermann, L.; Althammer, A.; Born, R. Angew. Chem., Int. Ed. 2006, 45, 2619-2622. (b) Ackermann, L.; Vicente, R.; Althammer, A. Org. Lett. 2008, 10, 2299-2302.

(29) Ackermann, L.; Althammer, A.; Fenner, S. Angew. Chem., Int. Ed. 2009, 48, 201-204.

(30) Hayashi, T.; Katsuro, Y.; Okamoto, Y.; Kumada, M. Tetrahedron Lett. 1981, 22, 4449-4452.

(31) Yoshikai, N.; Matsuda, H.; Nakamura, E. J. Am. Chem. Soc. 2009, 131, 9590-9599.

(32) Chen, H.; Huang, Z.; Hu, X.; Tang, G.; Xu, P.; Zhao, Y.; Cheng, C.-H. J. Org. Chem. 2011, 76, 2338-2344.

(33) Huang, J.-H.; Yang, L.-M. Org. Lett. 2011, 13, 3750-3753.

(34) Zhao, Y.-L.; Li, Y.; Li, Y.; Gao, L.-X.; Han, F.-S. Chem. - Eur. J. 2010, 16, 4991-4994.

(35) (a) De Carolis, M.; Protti, S.; Fagnoni, M.; Albini, A. Angew. Chem., Int. Ed. 2005, 44, 1232-1236. (b) Dichiarante, V.; Fagnoni, M.; Albini, A. Angew. Chem., Int. Ed. 2007, 46, 6495-6498.

(36) Sengupta, S.; Leite, M.; Raslan, D. S.; Quesnelle, C.; Snieckus, V. J. Org. Chem. 1992, 57, 4066-4069.

(37) Huang, K.; Yu, D.-G.; Zheng, S.-F.; Wu, Z.-H.; Shi, Z.-J. Chem. Eur. J. 2011, 17, 786-791.

(38) (a) Li, B.-J.; Xu, L.; Wu, Z.-H.; Guan, B.-T.; Sun, C.-L.; Wang, B.-Q.; Shi, Z.-J. J. Am. Chem. Soc. 2009, 131, 14656-14657. (b) Silberstein, A. L.; Ramgren, S. D.; Garg, N. K. Org. Lett. 2012, 14, 3796-3799.

(39) (a) Quasdorf, K. W.; Riener, M.; Petrova, K. V.; Garg, N. K. J. Am. Chem. Soc. 2009, 131, 17748-17749. (b) Nakamura, K.; Yasui, K.; Tobisu, M.; Chatani, N. Tetrahedron 2015, 71, 4484-4489. (c) Ohtsuki, A.; Yanagisawa, K.; Furukawa, T.; Tobisu, M.; Chatani, N. J. Org. Chem. 2016, 81, 9409-9414.

(40) Song, W.; Ackermann, L. Angew. Chem., Int. Ed. 2012, 51, $8251-8254$.

(41) Mesganaw, T.; Silberstein, A. L.; Ramgren, S. D.; Nathel, N. F. F.; Hong, X.; Liu, P.; Garg, N. K. Chem. Sci. 2011, 2, 1766-1771.

(42) Antoft-Finch, A.; Blackburn, T.; Snieckus, V. J. Am. Chem. Soc. 2009, 131, 17750-17752.

(43) Takise, R.; Itami, K.; Yamaguchi, J. Org. Lett. 2016, 18, 44284431.

(44) Shi, W.-J.; Zhao, H.-W.; Wang, Y.; Cao, Z.-C.; Zhang, L.-S.; Yu, D.-G.; Shi, Z.-J. Adv. Synth. Catal. 2016, 358, 2410-2416.

(45) Wang, Y.; Wu, S.-B.; Shi, W.-J.; Shi, Z.-J. Org. Lett. 2016, 18, $2548-2551$.

(46) Guan, B.-T.; Wang, Y.; Li, B.-J.; Yu, D.-G.; Shi, Z.-J. J. Am. Chem. Soc. 2008, 130, 14468-14470.

(47) Quasdorf, K. W.; Tian, X.; Garg, N. K. J. Am. Chem. Soc. 2008, $130,14422-14423$

(48) Li, B.-J.; Li, Y.-Z.; Lu, X.-Y.; Liu, J.; Guan, B.-T.; Shi, Z.-J. Angew. Chem., Int. Ed. 2008, 47, 10124-10127.

(49) Ehle, A. R.; Zhou, Q.; Watson, M. P. Org. Lett. 2012, 14, 12021205.

(50) (a) Takise, R.; Muto, K.; Yamaguchi, J.; Itami, K. Angew. Chem., Int. Ed. 2014, 53, 6791-6794. (b) Cornella, J.; Jackson, E. P.; Martin, R. Angew. Chem., Int. Ed. 2015, 54, 4075-4078. (c) Koch, E.; Takise, R.; Studer, A.; Yamaguchi, J.; Itami, K. Chem. Commun. 2015, 51, $855-857$.

(51) Zarate, C.; Martin, R. J. Am. Chem. Soc. 2014, 136, 2236-2239.

(52) Correa, A.; Leon, T.; Martin, R. J. Am. Chem. Soc. 2014, 136, $1062-1069$.

(53) (a) Yang, J.; Chen, T.; Han, L.-B. J. Am. Chem. Soc. 2015, 137, 1782-1785. (b) Yang, J.; Xiao, J.; Chen, T.; Han, L.-B. J. J. Org. Chem. 2016, 81, 3911-3916.

(54) Guo, L.; Hsiao, C.-C.; Yue, H.; Liu, X.; Rueping, M. ACS Catal. 2016, 6, 4438-4442.

(55) Wang, J.; Ferguson, D. M.; Kalyani, D. Tetrahedron 2013, 69, $5780-5790$.

(56) Shimasaki, T.; Tobisu, M.; Chatani, N. Angew. Chem., Int. Ed. 2010, 49, 2929-2932. 
(57) (a) Muto, K.; Yamaguchi, J.; Itami, K. J. Am. Chem. Soc. 2012, 134, 169-172. (b) Muto, K.; Hatakeyama, T.; Yamaguchi, J.; Itami, K. Chem. Sci. 2015, 6, 6792-6798.

(58) Kinuta, H.; Hasegawa, J.; Tobisu, M.; Chatani, N. Chem. Lett. 2015, 44, 366-368.

(59) (a) Wenkert, E.; Michelotti, E. L.; Swindell, C. S. J. Am. Chem. Soc. 1979, 101, 2246-2247. (b) Wenkert, E.; Michelotti, E. L.; Swindell, C. S.; Tingoli, M. J. Org. Chem. 1984, 49, 4894-4899.

(60) Dankwardt, J. W. Angew. Chem., Int. Ed. 2004, 43, 2428-2432. (61) (a) Tobisu, M.; Shimasaki, T.; Chatani, N. Angew. Chem., Int. Ed. 2008, 47, 4866-4869. (b) Tobisu, M.; Yasutome, A.; Kinuta, H.; Nakamura, K.; Chatani, N. Org. Lett. 2014, 16, 5572-5575.

(62) (a) Guan, B.-T.; Xiang, S.-K.; Wu, T.; Sun, Z.-P.; Wang, B.-Q.; Zhao, K.-Q.; Shi, Z.-J. Chem. Commun. 2008, 1437-1439. (b) Tobisu, M.; Takahira, T.; Chatani, N. Org. Lett. 2015, 17, 4352-4355.

(c) Tobisu, M.; Takahira, T.; Morioka, T.; Chatani, N. J. Am. Chem. Soc. 2016, 138, 6711-6714.

(63) (a) Tobisu, M.; Shimasaki, T.; Chatani, N. Chem. Lett. 2009, 38, 710-711. (b) Tobisu, M.; Yasutome, A.; Yamakawa, K.; Shimasaki, T.; Chatani, N. Tetrahedron 2012, 68, 5157-5161.

(64) Wang, C.; Ozaki, T.; Takita, R.; Uchiyama, M. Chem. - Eur. J. 2012, 18, 3482-3485.

(65) (a) Leiendecker, M.; Hsiao, C.-C.; Guo, L.; Alandini, N.; Rueping, M. Angew. Chem., Int. Ed. 2014, 53, 12912-12915. (b) Yang, Z.-K.; Wang, D.-Y.; Minami, H.; Ogawa, H.; Ozaki, T.; Saito, T.; Miyamoto, K.; Wang, C.; Uchiyama, M. Chem. - Eur. J. 2016, 22, $15693-15699$.

(66) Zarate, C.; Manzano, R.; Martin, R. J. Am. Chem. Soc. 2015, 137, 6754-6757.

(67) Tobisu, M.; Takahira, T.; Ohtsuki, A.; Chatani, N. Org. Lett. 2015, 17, 680-683.

(68) (a) Morioka, T.; Nishizawa, A.; Nakamura, K.; Tobisu, M.; Chatani, N. Chem. Lett. 2015, 44, 1729-1731. (b) Liu, X.; Hsiao, C.C.; Kalvet, I.; Leiendecker, M.; Guo, L.; Schoenebeck, F.; Rueping, M. Angew. Chem., Int. Ed. 2016, 55, 6093-6098.

(69) Nakamura, K.; Tobisu, M.; Chatani, N. Org. Lett. 2015, 17, 6142-6145.

(70) Kakiuchi, F.; Usui, M.; Ueno, S.; Chatani, N.; Murai, S. J. Am. Chem. Soc. 2004, 126, 2706-2707.

(71) Zhao, Y.; Snieckus, V. J. Am. Chem. Soc. 2014, 136, 1122411227.

(72) Cong, X.; Tang, H.; Zeng, X. J. Am. Chem. Soc. 2015, 137, 14367-14372.

(73) Iranpoor, N.; Panahi, F. Adv. Synth. Catal. 2014, 356, 30673073. For a similar nickel-catalyzed borylation of aryl and benzyl 2pyridyl ethers via C-O cleavage, see: Tobisu, M.; Zhao, J.; Kinuta, H.; Furukawa, T.; Igarashi, T.; Chatani, N. Adv. Synth. Catal. 2016, 358, 2417-2421. For a similar rhodium-catalyzed borylation of aryl 2pyridyl ethers through cleavage of the C-O bond, see: Kinuta, $\mathrm{H}$.; Tobisu, M.; Chatani, N. J. Am. Chem. Soc. 2015, 137, 1593-1600.

(74) Yu, D.-G.; Li, B.-J.; Zheng, S.-F.; Guan, B.-T.; Wang, B.-Q.; Shi, Z.-J. Angew. Chem., Int. Ed. 2010, 49, 4566-4570.

(75) Yu, D.-G.; Shi, Z.-J. Angew. Chem., Int. Ed. 2011, 50, 7097-7100.

(76) Barker, R. S. Preparation of aminated benzenes from hydroxy benzenes. Patent No. US3272865, 1966.

(77) Gharda, K. H.; Sliepcevich, C. M. Ind. Eng. Chem. 1960, 52, 417-420.

(78) McKechnie, I.; Bayer, F.; Drennan, J. Chem. Eng. (N. Y.) 1980, $29,26-27$.

(79) Becker, M.; Russell, J. L. Chem. Eng. (N. Y.) 1973, 80, 42-43.

(80) Mitchell, B.; Sargis, K. Process for the production of organic amines. Patent No. US3860650, 1975.

(81) Ono, Y.; Ishida, H. J. Catal. 1981, 72, 121-128.

(82) Chang, C. D.; Lang, W. H. Aniline or substituted aniline from phenol or phenolic compounds. Patent No. EP62542A1, 1982.

(83) Chang, C. D.; Perkins, P. D. Zeolites 1983, 3, 298-299.

(84) Yasuhara, M.; Matsunaga, F. Preparation of anilines. Patent No. US4987260, 1991.
(85) Mori, Y.; Noro, H.; Hara, Y.; Washama, T. Preparation of aromatic amines from phenols. Patent No. JP06184062A, 1994.

(86) Jiang, R.; Xie, Z.; Zhang, C.; Yang, Y.; Chen, Q. React. Kinet. Catal. Lett. 2005, 84, 215-221.

(87) Ma, J.; Wang, L.; Chen, L.; Dong, X.; Wang, L. Bentonite-based amination reaction catalyst preparation method. Patent No. CN103418373A, 2013.

(88) Deger, T. E.; Goshorn, R. H. Novel catalytic process for preparation of mercaptans by reaction of $\mathrm{H}_{2} \mathrm{~S}$ with alcohols or ethers. Patent No. US3035097, 1962.

(89) Sakurada, A.; Hirowatari, N. Aromatic sulfur compounds. Patent No. JP55036409A, 1980.

(90) Matsumura, Y. Preparation of thiols with high selectivity from hydroxy compounds and hydrogen sulfide. Patent No. JP2011126873A, 2011.

(91) Hamada, H.; Yamamoto, M.; Kuwahara, Y.; Matsuzaki, T.; Wakabayashi, K. Bull. Chem. Soc. Jpn. 1985, 58, 1551-1555.

(92) (a) Simon, M.-O.; Girard, S. A.; Li, C.-J. Angew. Chem., Int. Ed. 2012, 51, 7537-7540. (b) Girard, S. A.; Hu, X.; Knauber, T.; Zhou, F.; Simon, M.-O.; Deng, G.-J.; Li, C.-J. Org. Lett. 2012, 14, 5606-5609.

(93) (a) Sutter, M.; Duclos, M.-C.; Guicheret, B.; Raoul, Y.; Métay, E.; Lemaire, M. ACS Sustainable Chem. Eng. 2013, 1, 1463-1473. (b) Sutter, M.; Lafon, R.; Raoul, Y.; Métay, E.; Lemaire, M. Eur. J. Org. Chem. 2013, 2013, 5902-5916. (c) Sutter, M.; Sotto, N.; Raoul, Y.; Metay, E.; Lemaire, M. Green Chem. 2013, 15, 347-352.

(94) (a) Xie, Y.; Liu, S.; Liu, Y.; Wen, Y.; Deng, G.-J. Org. Lett. 2012, 14, 1692-1695. (b) Cao, X.; Bai, Y.; Xie, Y.; Deng, G.-J. J. Mol. Catal. A: Chem. 2014, 383-384, 94-100. (c) Chen, S.; Liao, Y.; Zhao, F.; Qi, H.; Liu, S.; Deng, G.-J. Org. Lett. 2014, 16, 1618-1621. (d) Xiao, F.; Liao, Y.; Wu, M.; Deng, G.-J. Green Chem. 2012, 14, 3277-3280. (e) Liao, Y.; Jiang, P.; Chen, S.; Xiao, F.; Deng, G.-J. RSC Adv. 2013, 3, 18605-18608. (f) Cao, X.; Cheng, X.; Bai, Y.; Liu, S.; Deng, G.-J. Green Chem. 2014, 16, 4644-4648. (g) Hajra, A.; Wei, Y.; Yoshikai, N. Org. Lett. 2012, 14, 5488-5491. (h) Izawa, Y.; Pun, D.; Stahl, S. S. Science 2011, 333, 209-213. (i) Hong, W. P.; Iosub, A. V.; Stahl, S. S. J. Am. Chem. Soc. 2013, 135, 13664-13667.

(95) Chen, Z.; Zeng, H.; Girard, S. A.; Wang, F.; Chen, N.; Li, C.-J. Angew. Chem., Int. Ed. 2015, 54, 14487-14491.

(96) Chen, Z.; Zeng, H.; Gong, H.; Wang, H.; Li, C.-J. Chem. Sci. 2015, 6, 4174-4178.

(97) Jumde, V. R.; Petricci, E.; Petrucci, C.; Santillo, N.; Taddei, M.; Vaccaro, L. Org. Lett. 2015, 17, 3990-3993.

(98) St. Amant, A. H.; Frazier, C. P.; Newmeyer, B.; Fruehauf, K. R; Read de Alaniz, J. Org. Biomol. Chem. 2016, 14, 5520-5524.

(99) (a) Cao, Z.-C.; Luo, F.-X.; Shi, W.-J.; Shi, Z.-J. Org. Chem. Front. 2015, 2, 1505-1510. (b) Ohgi, A.; Nakao, Y. Chem. Lett. 2016, 45, 45-47. (c) Shi, W.-J.; Li, X.-L.; Li, Z.-W.; Shi, Z.-J. Org. Chem. Front. 2016, 3, 375-379. 